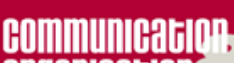
प1口.

\section{Communication et organisation}

Revue scientifique francophone en Communication organisationnelle

$54 \mid 2018$

Pratiques de la communication et Big Data

\title{
Fabien GRANJON (Dir.), Matérialismes, culture et communication. Tome 1 : Marxismes, théorie et sociologie critiques
}

Paris : Presses des Mines, 2016

Eloria Vigouroux-Zugasti

\section{OpenEdition}

\section{Journals}

Édition électronique

URL : https://journals.openedition.org/communicationorganisation/7317

DOI : 10.4000/communicationorganisation.7317

ISBN : 979-10-300-0341-3

ISSN : 1775-3546

Éditeur

Presses universitaires de Bordeaux

\section{Édition imprimée}

Date de publication : 1 décembre 2018

Pagination : 255-257

ISBN : 979-10-300-0340-6

ISSN : 1168-5549

Référence électronique

Eloria Vigouroux-Zugasti, « Fabien GRANJON (Dir.), Matérialismes, culture et communication. Tome 1 : Marxismes, théorie et sociologie critiques », Communication et organisation [En ligne], 54 | 2018, mis en ligne le 01 décembre 2018, consulté le 04 janvier 2023. URL : http://journals.openedition.org/ communicationorganisation/7317 ; DOI : https://doi.org/10.4000/communicationorganisation.7317 
émoticônes car elles tirent leur sens de la lecture phonétique des lettres qui les composent. Un ensemble de mots peut être qualifié d'interjection, tel que « ah, eh, oh » pour les interjections primaires et « Chic! hélas, Flûte! » pour les interjections secondaires (ou dérivées). Létude du corpus permet à Pierre Halté de dresser le constat de la similarité des valeurs sémantico-pragmatiques des émoticônes et des interjections. En effet, une interjection comme « ah! » qui marque la surprise a une signification proche de l'émoticône «oO » (deux yeux de face, ouverts différemment), qui suggère également la surprise. Les émoticônes et interjections ne se substituent par toujours, mais il est intéressant de noter qu'ils structurent le discours et révèlent les émotions du locuteur.

Pour conclure, précisons que la communication médiatisée par ordinateur fait l'objet de nombreuses recherches en linguistique, en sémiotique et en Sciences de l'Information et de la Communication. Louvrage de Pierre Halté propose une analyse originale des discours numériques par le prisme des marques modales contemporaines de l'énonciation. Si leur emploi n'est pas récent (les émoticônes sont apparus dans les années 80), un tel travail d'analyse nous montre les subtilités d'usage dont la compréhension modifie complètement notre rapport au texte. Les émoticônes sont finalement des « sortes de gestes à l'écrit » qui pallient la faiblesse du paralangage dans les discussions médiatisées par les TIC.

Laurène BECCUCCI

Laurène Beccucci est doctorante en Sciences de l'Information et de la Communication à l'Université Bordeaux Montaigne au sein du laboratoire MICA (EA 4426). Ses intérêts de recherche portent sur les formes de violence médiatisées par les TIC et leur prise en charge par les modérateurs. Elle travaille également sur les imaginaires genrés véhiculés dans les productions médiatiques.

Fabien GRANJON (Dir.), Matérialismes, culture et communication.

Tome 1 : Marxismes, théorie et sociologie critiques. Paris : Presses des Mines, 2016, 422 p. ISBN 978-2-35671-390-2, $35 €$.

L'ouvrage présenté ci-après est le premier volume d'une trilogie intitulée Matérialismes, culture et communication. Le présent tome, Marxismes, Théorie et sociologie critiques, a été coordonné par Fabien 
Granjon, Professeur en Sciences de l'Information et de la Communication à l'Université Paris VIII, spécialiste des médias numériques et de la sociologie critique de la communication. Louvrage s'insère dans un projet encyclopédique traitant des savoirs critiques matérialistes concernant la culture et la communication. Il s'agit, pour les auteurs $\mathrm{du}$ présent volume, de saluer les apports scientifiques des approches marxistes, de la théorie critique et de la sociologie de la domination culturelle, lesquels " prolongent et enrichissent l'héritage classique du matérialisme historique ». Ces travaux auraient ainsi permis d'ouvrir la voie aux études des phénomènes culturels et communicationnels à l'œuvre dans les sociétés capitalistes. Ce premier tome de la trilogie est interdisciplinaire, avec des contributeurs issus de différents domaines scientifiques : philosophie, politique, SIC, sociologie, psychologie, etc.

Louvrage se divise en quatre parties. La première met en perspective l'héritage marxiste, appliqué à l'idéologie (Isabelle Garo), à l'argent (Antoine Artous), à la question technique (Jean Vioulac) et à l'art (Jean-Marc Lachaud). Par exemple, Isabelle Garo analyse la perception $\mathrm{du}$ travail, tant manuel qu'intellectuel, au prisme de la conception marxiste de l'idéologie, en expliquant la manière dont Marx a enrichi la pensée des Lumières sur ce sujet.

La seconde partie «Marxismes, culture et médias » porte sur l'influence de Marx sur les concepts info-communicationnels : presse, culture, information, communication, etc. Ces contributions intéresseront particulièrement les lecteurs issus des SIC, avec de nombreuses références pouvant être mobilisées pour l'étude de la communication et du traitement médiatique de l'information. Les auteurs de la troisième partie proposent un tour d'horizon des principaux courants et penseurs s'inscrivant dans le paradigme de la théorie critique : Walter Benjamin, Jürgen Habermas ou encore Axel Honneth, pour n'en citer que quelquesuns. La quatrième partie, enfin, est consacrée à Pierre Bourdieu, au travers de quatre articles, certains portant sur les principaux concepts du sociologue (la distinction, les médias, le journalisme, etc.), d'autres faisant le lien entre Bourdieu et l'idéologie marxiste.

Nous souhaiterions insister sur la qualité de ce premier tome de Matérialismes, culture et communication. L'aspect interdisciplinaire de l'ouvrage apporte une richesse théorique et une finesse d'analyse qu'il convient de souligner. Les dimensions historiques, philosophiques ou encore scientifiques se mêlent et se démêlent, offrant une lecture captivante et passionnante. L'incessant recours à l'histoire (du marxisme, des auteurs 
étudiés, des contextes idéologiques, etc.) donne une ampleur dépassant la simple analyse scientifique. Ceci est fortement appréciable pour le lecteur, qui peut alors prendre plaisir à s'enrichir scientifiquement et culturellement.

Les thématiques choisies tendent à suivre un parti pris idéologique relativement prononcé, sans pour autant tomber dans l'excès ou dans le prosélytisme. L'ouvrage s'inscrit dans une démarche informative argumentée, en proposant des analyses et des lectures de la sociologie marxiste que le lecteur peut choisir de ne pas suivre. Ainsi, bien quétant politiquement et scientifiquement engagés, les auteurs parviennent à préserver la liberté d'opinion et d'analyse du lecteur. L'abondance des références (historiques, scientifiques, idéologiques, etc.) représente l'un des atouts majeurs de ce tome. L'article de Fabien Granjon sur Vladimir Ilitch Lénine, par exemple, suscite la curiosité du lecteur au sujet de Lénine, au point d'aller effectuer quelques recherches complémentaires pour sa culture personnelle. La richesse des idées, la fluidité de la rédaction et l'effort de contextualisation scientifico-historique donnent à l'ensemble une forme romanesque : l'ouvrage ne se lit pas tant comme une compilation d'articles que comme un roman sur l'histoire de la pensée marxiste et de la théorie critique.

Roman qui, malgré tout, reste quelque peu difficile à prendre en main. Effectivement, il présente les défauts de ses qualités : si les apports scientifiques et historiques contribuent à la force des propos, ils augmentent également la difficulté du lecteur à s'en saisir.Il est ainsi nécessaire pour ces derniers de disposer d'une culture générale marquée pour appréhender la richesse de l'ouvrage, malgré l'effort des auteurs pour le rendre accessible. L'ensemble du livre demande un certain effort de compréhension, voire des recherches annexes, pour être en mesure d'en apprécier la valeur. Les lecteurs dépassant ces difficultés en seront récompensés. Matérialismes, culture et communication est un ouvrage digne d'intérêt. D'une qualité théorique et rédactionnelle rare, il appelle, comme tout bon ouvrage, à la (re)lecture.

\section{Eloria VIGOUROUX-ZUGASTI}

Eloria Vigouroux-Zugasti est docteure en Sciences de l'Information et de la Communication, ATER à l'Université Paris-Est Marne-La-Vallée et chercheure associée au laboratoire MICA (EA 4426) et au laboratoire DICEN (EA 7339). 